\title{
An Implementation Strategy For Developing Interdisciplinary Professional Skills Within The Accounting Curriculum
}

Joseph M. Ragan, (E-mail: jragan@sju.edu), Saint Joseph’s University

\begin{abstract}
Accounting students are aware of the increasing demand generated from the use of Enterprise Resource Planning (ERP) systems within the world's major companies. This paper describes the use of this technology within an undergraduate accounting curriculum. The objective is to teach business processes and integration issues. Students simulated a manufacturing ERP implementation by organizing themselves as an implementation team, developing an implementation plan, designing a simple product and product structures, populating the master records, and executing a system walk-through. Students also script core business processes and develop a demonstration of their implementation system for interested parties in the business school. The paper evaluates the implementation project and offers suggestions for enhancing the benefits capable from such pedagogy.
\end{abstract}

\section{INTRODUCTION}

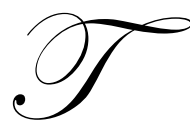

his paper describes an ERP course project completed by students in an undergraduate accounting systems course. The course featured the use of SAP R/3 Software, contributed and supported by SAP America. SAP offers a University Alliance Program, of which we are members. The primary objectives of this project were to provide students with an opportunity to: (1) better understand core business processes and their organizational linkages, (2) gain confidence in developing a systems-based project, (3) improve information analysis and problem solving skills, (4) develop and improve communication and documentation skills, and (5) gain a greater understanding of manufacturing environments.

The course consisted of 88 undergraduate accounting majors. The course was broken down into three classes. A STAR Scholar and an associate STAR Scholar are chosen for each team. The newly chosen STAR Scholars proceed to lead the group in a discussion to clarify project objectives and define a product line they would be responsible for. The team leader then facilitates the organization of students into the following functional teams: (1) Sales, Marketing \& Distribution, (2) Procurement, Production \& Engineering, and (3) Accounting \& Controlling.

Student teams were given the same basic training using an integrated case (IDES) provided by SAP, which led students through the processes supported by the software, including order entry, MRP, procurement, manufacturing, shipping and billing. After basic training, the functional teams went to work to develop the structure and master data required to support their respective processes. The manufacturing and engineering team, for example, developed a simplified product design and entered the product structure into the ERP System. This would then require the materials management team (using the Bill of Materials) to establish the detail of the material master files. The sales and distribution team, relying on information needed for a standard order, would build a series of customer master files. As part of the deliverables required for this stage, the functional teams were required to gain a detailed understanding of their core process so that they could prepare process models and scripts that would facilitate future training in systems operations. The teams developed scripts consisting of process overviews and including appropriate procedures, diagrams and graphics, which guided the user through the various core processes. 
Having completed their data conversion and process modeling phases, the student team would turn over their materials to another team from a different group, whose job it was to conduct the walk-through. This consisted of following the various integrated scripts through the system to determine if the data structures have been properly configured and noting the integrative impact of the transaction on each functional area.

\section{CURRICULUM INNOVATIONS}

Pedagogical revisions to the undergraduate curriculum in Accounting at the Haub School of Business encompass two broad categories. First, a newly created three-course sequence encompassing Intermediate and Advanced Accounting has been prepared. These courses are newly titled as FAIS I, II, and III. The three-course sequence focus is a single continuous learning experience traversing sophomore to junior year. Each course will progressively build upon and expand the knowledge base acquired in the prior course. This knowledge base will include topical content in Accounting and application ability within SAP R/3. Second, another group of courses taught in the sophomore year incorporates subject matter inherent to cost and managerial accounting. These courses are titled MAIS I and II. The SAP exposure afforded students within these course sequences will provide hands on experiences in a team-oriented format within a business case context. It is envisioned that a single business case will be used throughout these five courses.

\section{COLLABORATIVE LEARNING MODEL (STAR SCHOLARS)}

A unique feature of the course pedagogy is the utilization of STAR Scholars to assist in development and delivery of various SAP scenarios. These scholars are chosen through a highly selective process and specially trained to deal with these application scenarios. To date, there are some twenty-eight STAR Scholars comprised mostly of juniors and senior undergraduate majors. These students are compensated for the work done in class and are provided with enrichment activities, such as field visits and special speakers, helping them to understand the essentiality of implementation of state of the art software. They often participate in research-based projects designed and developed by faculty. In addition, STAR Scholars involve themselves in a series of special activities under the direction of a Faculty mentor. Developing scenarios of various computer applications involving Enterprise Resource Planning software and SAP are included. In addition, seminars with entrepreneurs and technology leaders to provide opportunities to interact on a personal and informal level are held with business leaders. Sponsored participation in special events with alumni working in technology and consulting fields is also a component. These students assist in classroom delivery and continue to service the course by maintaining a help desk for students.

\section{PHASES OF THE CURRICULUM ROLLOUT}

The courses are three-credit courses required for all accounting majors, typically in the sophomore and junior years. SJU requires all students to have laptops. A typical class consists of 30 students and is taught over a fourteen week semester. The university is a member of the SAP Alliance. As a member of the University Alliance, SJU is given access to SAP R/3 in real time (24/7) through the University of Wisconsin at Milwaukee. The objectives of the curriculum rollout were agreed upon by the department faculty in advance.

\section{Phase I - Purchasing Phase}

The objectives established for this phase were to better understand core business processes and their linkage to accounting. The purpose of bringing SAP into the classroom further demonstrates how the roles of accountants have changed with technology. No longer do accountants simply add and subtract, they interpret business situations and use information to make decisions. It was found that using the concept of scenarios was the most ideal way to bring business situations using SAP R/3 into the classroom and have the students enter the information, master data and transactions, then see how the system uses the information, and finally use the information to make decisions for the business.

Scenarios are written in the form of scripts and tested by the STAR Scholars prior to their use in class. Students just follow the script to complete the process. The typical project takes them through the following steps; 
master file $\rightarrow$ process $\rightarrow$ report $\rightarrow$ analyze. First they create a master file, for example, a vendor master file. The students are usually asked to select a name that they will be able to identify with and remember (such as using their last name). The report would be affected by the transaction they will do in the following step. By going to the report before going through the process students see what the number was before the transaction, so when they access the report after the transaction, they can see the difference the process made. This enables the students to better analyze the effects of the process they went through. The last step is analyzing the process in terms of the effects it had on the business.

It was found that giving the students a script that has been written out and tested gives them a path to follow so they do not get lost in the vastness that SAP creates. After completing the scenario as it is written, students feel more comfortable working in the modular area in which the scenario operates. There is no such thing as an SAP expert, but there are experts in certain modules. This course was designed, not to create experts but, to make students feel comfortable when operating within the system.

A good way to create interest for the students is to use the email function within the system. This is done by emailing a question from our hypothetical employee, such as a CEO, CFO, etc., asking a question pertaining to the scenario to be performed in class. After the scenario is performed the students respond to the question which forces them to explain the task they performed and how it affected the business. Each student's response will contain an attached report, which will give the instructor enough information to give the student credit for the assignment.

It is essential for students to understand the relationship between the concept coverage within the text and the applications within SAP. A very simple overview of SAP navigation is completed in this process. The students leave with a scavenger hunt assignment using SAP navigation. Students are also introduced to the faculty website and the blackboard location for course documents and assignments. Using SAP R/3, students can now begin a walk through of the topics in the first accounting course. These topics primarily include financial statement reporting and assets. As each topic is reviewed, assignments are handed out for completion by the students, and subsequently graded.

\section{Phase II - Asset Reporting Phase}

The objective of this phase is to improve information system problem solving skills using performance reports. In this phase the role of technology as a cost controller is introduced to students. The major topics in a typical Cost Course emphasize volume cost profit behavior analysis, capital budgeting, and responsibility accounting. The scenarios written in these areas give students the opportunity to create a budget around a cost center and, as a team, measure performance and determine direction. This is done through team-based case simulations (as they now appear on the CPA exam) where students are asked to advise a client what to do regarding product cost overruns and low profitability. Student assessment surveys indicate students have a renewed appreciation on how accounting information affects management decision making and see the role non financial metrics play in shaping the performance and direction of the firm. Significant attention must be paid to the grading process in this phase. Students are not just graded in a normal test mode, but also are assessed points based on innovative and creative solutions communicated succinctly and efficiently to managers. A team presentation of project outcomes helps bring closure to the course and leads to conclusions that are often contingent and uncertain. This unstructured analysis often frustrates students.

\section{Phase III - Analysis Phase}

Students are provided a series of application problem scenarios where they have to provide information reports on the performance of a series of products. They must also then be able to drill down to each component to determine contribution profit and costs. Each case is graded competitively based on project presentation correct solution and clarity of information. Post surveys indicate real satisfaction with the group work and desire to make the course even more case oriented. Given the case orientation, grades tend to be higher than a normal advanced cost accounting course. The ultimate goal here is to make decisions that lead as directly as possible to benefits. 


\section{EVALUATING STUDENT PERFORMANCE}

Points are assigned to each student project for both individual assignments and the group presentation. To determine whether or not the students have completed the individual assignments, inside or outside of the classroom, the SAP R/3 system is used. There are two methods used to help keep track of what the students have completed. First, the students are given control numbers that are used throughout the semester. These numbers are used when creating their master files so that they are easier to find within the system. Second, the students have used their own names when creating master files.

The system has controls built in that enable the ability to track what user names have completed assignments. There are two ways to do this: the students can send an email using the system, and attach a transaction file number or master file number, so that it is then possible to look up those individual files in the system or, a list could be brought up that will show all the files created by the students. For individual projects, the latter is found to be more efficient. For example, if the students' assignment is to create a cash account, a balance sheet account can be accessed, that has all the cash accounts listed, so it can be determined which students completed the assignment correctly and which did not. Because control numbers are used, and the accounts are listed in sequential order, it is easy to see which students failed to complete the assignment.

In addition to the project assignment questions, referencing and using SAP as an example to demonstrate text book material are also used on exams. Therefore, students must not only understand the textbook concepts, but also be able to identify examples using their experience with SAP to determine how this is useful or necessary for a system. A sample of work has been chosen from a student's electronic portfolio and is included in Appendix I.

\section{THE ACCOUNTING AND CONTROL REPORTS}

A key feature to this approach is to educate students on the fact that if information is properly processed, the reporting process will automatically create useful, robust and integrative information that should be of great use to functional business users. SAP R/3 contains more that 3,000 standard reports. Before exploring approaches to standard reports, the students must understand the basic reporting landscape within SAP R/3. Standard reports are available in the application areas where users are likely to need them. Reports are also available in standard repositories. Feedback from previous iterations of this project taught us that reports specification using the first approach was always more preferred. In short, we teach students how to find reports within their application modules using the very intuitive SAP standard menu.

A really neat feature of ERP is drilldown reporting. This contains interactive functionality that lets you analyze the data collected in your application system. Compared with other reporting tools, the drilldown reporting capability offers greater flexibility in mining data. You can slice and dice data without restrictions, or format it without fixed reports. Drilldown reporting allows you to: (1) choose key figures or performance measures to categorize your data, (2) display a number of objects for one key figure, (3) display a number of figures for one key object, and (4) carry out any number of deviation analyses (plan vs. actual, fiscal year comparison, etc.).

\section{PRESENTATION AND POST-IMPLEMENTATION REVIEW}

The project team presents its results in the final class session. In addition to the project team, several corporate/consultants from the accounting advisory board were in attendance. The session consisted of a project overview, a demonstration of the ERP Software, test of process functionality, a review of reports and a postimplementation review. Students also completed a brief post-implementation questionnaire to elicit their reaction to the project (Appendix II).

A major objective of the project was to provide an integrative experience in which students gained a better understanding of core business processes and the linkages among them. Overall, this objective appeared to be achieved at a satisfactory level (see Appendix II, \#1, 3, 4, 6, 13). The reporting activity forced students to look at dollar impact and financial results of process decision-making. Student readily saw how comprehensive ERP 
Software could tie the processes of an organization together (see Appendix II, \#11, 12, 20). While all the students appeared to grasp the integrative elements of the ERP System, not all students felt the project taught them the necessary process steps to effective do SAP on their own (see Appendix I, \#7, 8, 9, 18). Functional specialization (stove piping) did creep into team activities. Team members were allowed to focus too narrowly on their own functional departments and tended not to become very proficient with the parts of the ERP System that lay outside their boundaries.

A greater emphasis needs to be placed on tomorrow's students and what skills they gain in the classroom. In the mist of the post-implementation questionnaire, vital questions tested the usefulness of ERP Systems in today's accounting curriculum. These questions focused on the core business processes. With 93.6\% (see Appendix, \#20) of the students agreeing that ERP Systems are critical success factors in today's expanding global market and an average of $76.6 \%$ (see Appendix, \#11,12) of the students agreeing that vital decisions and evaluations are required of the applied business processes, one can argue that continuous knowledge and technological growth are key components in college and real-world atmospheres. The benefits of understanding and mainstreaming business processes into the day-to-day operations includes: increasing tangible value and reducing costs. With the opportunity of becoming more familiar with the system and making better decisions, their post-implementation review is a glimpse of maintaining a company's effectiveness and efficiency.

In their post-implementation review, students concluded on the final examination that the success of ERP in the business world depended on many of the same critical factors around which they judge success as students. First, the project must receive top management support with clear direction and understanding of what was required at each level of the project. A second critical success factor was iterative testing of the core processes within SAP $\mathrm{R} / 3$. The third significant factor was in the financial analysis and control reporting done with effective communication of results to project team members (see Appendix I).

\section{SUMMARY AND CONCLUSION}

In this article, we described and examined a unique approach to teaching enterprise process integration and reporting. This approach entails the use of a fictitious model company and its simultaneous implementation of an ERP System. Benefits derive from the fact that students have multiple exposures to a single company, allowing them to become familiar with its products, manufacturing processes and its industry. Each student has the opportunity to examine the company at different functional perspectives while remaining cognizant of the corporation as a whole. This cross-functional approach provides insight into other disciplines, allowing students to gain a real appreciation of business decision-making using integrative technology.

\section{REFERENCES}

1. Albrecht, W. Steve, and Robert J. Sack. Accounting Education: Charting the Course Through a Perilous Future. Sarasota, FL: American Accounting Association, 2000.

2. Antonucci, Y.L., Corbitt, G., Stewart, G. and Harris, A.L. 2004. Enterprise Systems Education: Where are we? Where are we going? Journal of Information Systems Education 15(3), 227-234.

3. Antonucci, Yvonne Lederer, and Michael Zur Muehlen. Developing An International Business to Business Process Curriculum: Extending the Classroom Walls with ERP Software. In the Proceedings of IESCON 2000, 17, (2000): Philadelphia.

4. Bendoly, E. and Schoenherr, T. 2005. ERP System and implementation-process benefits: Implications for B2B e-procurment. International Journal of Operations and Production Management. 25(4).

5. Bendoly, E. and Kaefer, F. 2004. Business technology complementarities: Impacts of the presence and strategic timing of ERP on B2B e-commerce technology efficiencies. Omega 32(5), 395-405.

6. Bendoly, E., Soni, A. and Venkataramanan, M.A.2004. Value chain resource planning: Adding value with systems beyond the enterprise. Business Horizons, 47(2), pp.79-86.

7. Brown, C.V., and I. Vessey. Managing the Next Wave of Enterprise Systems: Leveraging Lessons from ERP. MIS Quarterly Executive 2.1 (2003): 65-77. 
8. Corbitt, Gail, and James Mensching. Integrating SAP R/3 into a College of Business curriculum: Lessons learned. Information Technology and Management 1.4 (2000): 247-258.

9. Davenport, T.H., and M.C. Beers. Managing information about processes. Journal of Management Information Systems 12.1 (1995): 57-80.

10. Davenport, T.H., and Cantrell, S. 2002. The Return of Enterprise Solutions, Accenture.

11. David, Julie Smith, Harriet Maccracken, and Philip M.J. Reckers. Integrating Technology and Business Process Analysis into Introductory Accounting Courses. Issues in Accounting Education 18.4 (2003): 417 425.

12. Dickson, Gary W., and Albert Segars. Redefining the High-Technology Classroom. Journal of Education for Business 74.3 (1999): 152-156.

13. Fedorowicz, Jane, Ulric J. Gelinas, Jr., Catherine Usoff, and George Hachey. Twelve Tips for Successfully Integrating Enterprise Systems Across the Curriculum. Journal of Information Systems Education 15.3 (2004): 235-244.

14. Guthrie, Rand W., and Ruth A. Guthrie. Integration of Enterprise System Software in the Undergraduate Curriculum. In the Proceedings of IESCON 2000, 17, (2000): Philadelphia.

15. Hawkings, P. McCarthy, B., and Stein, A. 2004. Second wave ERP education. Journal of Information Systems Education 15(3), 327-332.

16. Joseph, George, and Asha George. ERP, learning communities, and curriculum integration. Journal of Information Systems Education 13.1 (2002): 51-58.

17. Lambrecht, Judith J. Teaching Technology-Related Skills. Journal of Education for Business 74.3 (1999): 144-151.

18. Strand, Carolyn A., Sandra T. Welch, Sarah A. Holmes, and Steven L. Judd. Developing Student Abilities to Recognize Risk Factors: A Series of Scenarios. Issues in Accounting Education 17.1 (2002): 57-67.

\section{APPENDIX I}

\section{A Student's Perspective: Lessons Learned}

Art Vandalay is the simulated Chief Executive Officer of IDES and throughout the semester; students emailed him continuous updates about the company. The e-mails he received included some of the following: memorandums, journal entries, reports and Excel analysis projects. One of the students in the class and STAR Scholar, Samantha Hauptman provided an e-mail (see Appendix I.I), which allowed for valuable feedback on the course and served as an assessment of learning for future SAP enhancement projects. She also provided an attachment within SAP's e-mail system that displays a Capital Budgeting Analysis (see Appendix I.II) that was exported from SAP into Microsoft Excel. This analysis allows for "what-if" scenarios in the calculation of Net Present Value (NPV). And finally, Samantha shows how she went through the process of retiring the asset she purchased. The journal entry associated with her delivery truck depicts the largest entry our students have ever seen within the SAP System. They are able to see the all proceeds, depreciation and tax associated with the retirement. 


\section{Assessment of SAP (Appendix I.I)}

\section{Assessment of SAP}

\begin{tabular}{llll}
\hline Created & $\equiv$ Samantha Hauptman & on $04 / 16 / 2006$ & $22: 05: 19$ \\
Changed & $\equiv$ Samantha Hauptman & on $04 / 16 / 2006$ & $22: 39: 43$
\end{tabular}

Art,

Over the past 11 weeks, I have used SAP and have noticed many strengths and weaknesses in its service as an information system. SAP is a strong integrative tool in the workplace that allows for the connection to many different modules. This is useful because once you input information once; it automatically transfers the information to all other areas so it minimizes redundant data input. These multiple modules allow managers to more accurately assess the performance of the company because SAP keeps track of both financial and nonfinancial data. Another one of SAP's strengths is that it displays messages on the bottom of the screen once an item has been created, saved, or posted. Related to this are the internal controls within SAP. Document flows, drill downs, and the "hat" button give auditors ample information about who created, approved, received etc. and the steps followed. SAP can also run simulations of different sales plans, depreciation methods, and production plans. This, and other interactive graphics within SAP, give the managers solutions to different scenarios and allow for appropriate forecasting. SAP allows for access to the production order, sales order, etc via links throughout the system. For example, you can access the purchase order from the asset explorer.

There are, however, some weaknesses in SAP. First, to get to a specific screen, you may have to go through a dozen menus or memorize many transaction codes. This can be time-consuming and inefficient. There are also minor glitches in the system such as language code errors and failing to state that a change has been saved at the bottom of the screen. Although SAP does run simulations, in order to do a proper analysis, such as a production variance report or capital budgeting analysis, you must export the information into Excel and then do the calculations. This should be able to be done in SAP without having to export the data and perform the calculations on your own. A larger problem with SAP is its implementation. SA.P doesn't adjust to your company or industry, you have to adjust your company to fit SAP. The information system is costly and needs the proper training and roll out in order to be successful.

Overall, SAP is a good information system that gives businesses a competitive advantage, but, like any of its competitors, it still has its weaknesses.

$\mathrm{SH}$ 
Capital Budgeting Analysis (Appendix I.II)

\begin{tabular}{c|l|c|c|c|c|c|c|c|}
\hline & \multicolumn{1}{|c|}{ A } & B & C & D & E & F & G \\
\hline 1 & Fiscal year & Ordinary Deprec. & Net Book Value & Currency & Taxable Inc. & Tax Exp. & Net CF After Tax \\
\hline 2 & 2006 & $(12,667.00)$ & $67,333.00$ & USD & $17,333.00$ & $2,599.95$ & $27,400.05$ \\
\hline 3 & 2007 & $(16,000.00)$ & $51,333.00$ & USD & $14,000.00$ & $2,100.00$ & $27,900.00$ \\
\hline 4 & 2008 & $(16,000.00)$ & $35,333.00$ & USD & $14,000.00$ & $2,100.00$ & $27,900.00$ \\
\hline 5 & 2009 & $(16,000.00)$ & $19,333.00$ & USD & $14,000.00$ & $2,100.00$ & $27,900.00$ \\
\hline 6 & 2010 & $(16,000.00)$ & $3,333.00$ & USD & $14,000.00$ & $2,100.00$ & $27,900.00$ \\
\hline 7 & 2011 & $(3,333.00)$ & 0.00 & USD & $26,667.00$ & $\mathbf{4 , 0 0 0 . 0 5}$ & $25,999.95$ \\
\hline 8 & & & & & & & \\
\hline 9 & Assumptions & & & & & & \\
\hline 10 & Initial Investment: & $80,000.00$ & & & & & \\
\hline 11 & Cash flow per year: & $30,000.00$ & & & & & & \\
\hline 12 & Tax rate: & $15 \%$ & & & & & & \\
\hline 13 & Discount Rate: & $12 \%$ & & & & & & \\
\hline 14 & & & & & & & & \\
\hline 15 & NPV: & & & & & & \\
\hline 16 & & & & & & & \\
\hline 17 & NPV after Initial & $\$ 33,299.26$ & & & & & \\
\hline 18 & Investment: & & & & & & & \\
\hline
\end{tabular}

Delivery Truck - Asset Retirement Journal Entry (Appendix I.III)

\begin{tabular}{|c|c|c|c|c|c|c|c|c|c|c|c|}
\hline \multicolumn{3}{|c|}{$\begin{array}{l}\text { Doc. Number } \\
\text { Doc. date } \\
\text { Doc.currency }\end{array}$} & $\begin{array}{l}100000507 \\
04 / 13 / 2006 \\
\text { USD }\end{array}$ & $\begin{array}{ll}\text { posting ) } & \text { Normat doc } \\
507 & \text { Company co } \\
2006 & \text { Posting da }\end{array}$ & $\begin{array}{l}3000 \\
04 / 13 / 2006\end{array}$ & & \multicolumn{2}{|l|}{ year } & & & \\
\hline Itm & PK & Cocd & Account & iccount short text & Bmount in LC & Crey & Amount & Crcy & LC2 amount & LCur2 & Cost Ctr \\
\hline $\begin{array}{l}1 \\
2 \\
3 \\
4 \\
5 \\
6 \\
7 \\
8\end{array}$ & $\begin{array}{l}01 \\
50 \\
50 \\
50 \\
50 \\
75 \\
40 \\
50\end{array}$ & $\begin{array}{l}3000 \\
3000 \\
3000 \\
3000 \\
3000 \\
3000 \\
3000 \\
3000 \\
3000\end{array}$ & $\begin{array}{l}3000 \\
820000 \\
175001 \\
175002 \\
175004 \\
21000 \\
825000 \\
250000\end{array}$ & $\begin{array}{l}\text { Thomas Bush Inc. } \\
\text { Proceeds from dispos } \\
\text { Sales Tax Level } 1 \\
\text { Sales Tax Level } 2 \\
\text { Sales Tax Level } 4 \\
\text { 000000003526 } 0000 \\
\text { Suspense a/c - dispo } \\
\text { Profits on disposal/ }\end{array}$ & $\begin{array}{r}80,000.00 \\
74,245.95- \\
4,640.37- \\
556.84- \\
556.84- \\
44,000.00- \\
74,245.95 \\
30,245.95-\end{array}$ & $\begin{array}{l}\text { USD } \\
\text { USD } \\
\text { USD } \\
\text { USD } \\
\text { USD } \\
\text { USD } \\
\text { USD } \\
\text { USD }\end{array}$ & $\begin{array}{r}80,000.00 \\
74,245.95- \\
4,640.37- \\
556.84- \\
556.84- \\
44,000.00- \\
74,245.95 \\
30,245.95- \\
0.00\end{array}$ & $\begin{array}{l}\text { USD } \\
\text { USD } \\
\text { USD } \\
\text { USD } \\
\text { USD } \\
\text { USD } \\
\text { USD } \\
\text { USD } \\
\text { USD }\end{array}$ & & & \\
\hline * * & & & & & & & 0. 80 & USD & & & \\
\hline
\end{tabular}




\section{APPENDIX II}

\section{Assessment of Learning}

With 88 students enrolled in the Managerial Accounting Information Systems II course, the responses needed for a successful survey need to be somewhere between $40 \%$ and $50 \%$ of the student population. The standards were very well met as $54 \%$ of the students responded to the survey questions associated with their involvement with SAP and the IDES project. Students agreed on all questions, ranging from $72.4 \%$ to as high as $97.8 \%$. It was a task that measures the essential value of core processes within the accounting curriculum.

\section{Student Survey Questions for Case Study}

This survey will help describe an ERP class project completed by students in an undergraduate accounting systems class. Based on your experience in Management Accounting Information Systems II, please pick the best answer for the questions listed below. Submissions will remain confidential. Thank you for your participation!

\section{Instructions:}

- Please indicate your answers to the case evaluation questions listed below by entering a single score (a, b, c, etc.) per question.

- $\quad$ Feel free to make additional statements about the case after answering the survey questions.

- Your answers will not be graded, feel free to express your opinion. Your honesty and insights will help to improve the case in the future.

- Each question allows for one response, various choices are listed below each question.

1. The case material (i.e. - IDES) was well written and could be easily understood.
a. Strongly Disagree $-2.1 \%$
b. Disagree $-0 \%$
c. Neutral $-4.3 \%$
d. Agree $-42.6 \%$
e. Strongly Agree $-\mathbf{5 1 . 1 \%}$

2. The grade percent allocated to the SAP homework assignments were an appropriate weight given the work required.
a. Strongly Disagree - 0\%
b. Disagree $-8.5 \%$
c. Neutral $-2.1 \%$
d. Agree $-27.7 \%$
e. Strongly Agree $-61.7 \%$

3. The level of difficulty of the case material was appropriate.
a. Strongly Disagree $-0 \%$
b. Disagree $-2.1 \%$
c. Neutral $-12.8 \%$

\section{d. Agree $\mathbf{- 5 5 . 3 \%}$ \\ e. Strongly Agree $-29.8 \%$}

4. The use of this case material supplemented my understanding of enterprise system concepts.
a. Strongly Disagree $-2.1 \%$
b. Disagree $-4.3 \%$
c. Neutral $-17 \%$
d. Agree $\mathbf{- 4 8 . 9 \%}$
e. Strongly Agree $-27.7 \%$

5. The material used throughout this course should be continued by the instructor.
a. Strongly Disagree $-2.1 \%$
b. Disagree $-2.1 \%$
c. Neutral $-8.5 \%$
d. Agree $-38.3 \%$
e. Strongly Agree $\mathbf{- 4 8 . 9 \%}$

6. Using the case material made coverage of enterprise system concepts more interesting.
a. Strongly Disagree $-2.1 \%$
b. Disagree $-2.1 \%$
c. Neutral $-12.8 \%$
d. Agree $-34 \%$
e. Strongly Agree $-48.9 \%$

7. Because of the competency exam I better understand the relationship between enterprise systems and business processes.
a. Strongly Disagree $-6.4 \%$
b. Disagree $-6.4 \%$
c. Neutral $-14.9 \%$
d. Agree-48.9\%
e. Strongly Agree $-23.4 \%$

8. After working with the case material I am more competent at using enterprise systems.
a. Strongly Disagree - 0\%
b. Disagree $-2.1 \%$
c. Neutral $-10.6 \%$ 


\section{d. Agree $-\mathbf{4 4 . 7 \%}$}

e. Strongly Agree $-42.6 \%$

9. The case material increased my knowledge related to enterprise system terms and definitions.
a. Strongly Disagree $-0 \%$
b. Disagree $-2.1 \%$
c. Neutral $-4.3 \%$
d. Agree - $46.8 \%$
e. Strongly Agree $\mathbf{- 4 6 . 8 \%}$

10. The SAP homework assignments required me to describe and explain enterprise system principles and theories.
a. Strongly Disagree $-2.1 \%$
b. Disagree $-8.5 \%$
c. Neutral $-6.4 \%$
d. Agree $\mathbf{- 4 4 . 7 \%}$
e. Strongly Agree $-38.3 \%$

11. The case material required me to apply business process thinking to a specific scenario reviewed in class.
a. Strongly Disagree $-0 \%$
b. Disagree $-10.6 \%$
c. Neutral $-19.1 \%$
d. Agree $\mathbf{- 4 4 . 7 \%}$
e. Strongly Agree $-25.5 \%$

12. The SAP homework assignments helped me to make evaluations and judgments about business process functions and activities.
a. Strongly Disagree $-4.3 \%$
b. Disagree $-2.1 \%$
c. Neutral $-10.6 \%$
d. Agree $\mathbf{- 5 7 . 4 \%}$
e. Strongly Agree $-25.5 \%$

13. Overall, I think the IDES case study is a clean and useful project.
a. Strongly Disagree $-2.1 \%$
b. Disagree $-0 \%$
c. Neutral $-6.4 \%$
d. Agree - 53.2\%
e. Strongly Agree $-38.3 \%$

14. The amount of work on the case material was justified based on the learning derived.
a. Strongly Disagree $-4.3 \%$
b. Disagree $-2.1 \%$
c. Neutral $-8.5 \%$
d. Agree $\mathbf{- 5 5 . 3 \%}$
e. Strongly Agree $-29.8 \%$

15. Which module did you enjoy the most?
a. Materials Management $-10.6 \%$
b. Production $-25.5 \%$
c. Sales \& Distribution $\mathbf{- 4 0 . 4 \%}$
d. Fixed Assets $-23.4 \%$

16. Which module did you enjoy the least?
a. Materials Management $-40.4 \%$
b. Production $-8.5 \%$
c. Sales \& Distribution $-6.4 \%$
d. Fixed Assets $\mathbf{- 4 4 . 7 \%}$

17. Indicate your gender.
a. Male $\mathbf{- 5 3 . 2 \%}$
b. Female $-46.8 \%$

18. I am comfortable using technology (i.e. - SAP, Excel, etc.)
a. Strongly Disagree $-0 \%$
b. Disagree $-0 \%$
c. Neutral $-2.1 \%$
d. Agree $-48.9 \%$
e. Strongly Agree $-\mathbf{4 8 . 9 \%}$

19. What was the total time in hours that you personally spent on the SAP case material?
a. 0 to $3-10.6 \%$
b. 4 to $6-21.3 \%$
c. 7 to $9-31.9 \%$
d. 10 to $12-21.3 \%$
e. 13 or more $-14.9 \%$

20. ERP Systems are critical success factors in today's expanding global market.
a. Strongly Disagree $-2.1 \%$
b. Disagree $-0 \%$
c. Neutral $-4.3 \%$
d. Agree $-34 \%$
e. Strongly Agree $\mathbf{- 5 9 . 6 \%}$ 